\title{
Regime de irrigação e palha influenciam na eficácia de herbicidas pré-emergentes no controle de capim-amargoso?
}

\author{
Daniela Maria BARROS ${ }^{1}$, Paulo Vinicius da SILVA ${ }^{1}$, Heráclito Lazari MEURER ${ }^{1}$, \\ Letícia da Silva Santos MEURER ${ }^{1}$, Edson Rocha DOMINGOS${ }^{1}$, Roque de Carvalho DIAS², \\ Estela Maris INÁCIO ${ }^{1}$, Patrícia Andrea MONQUERO ${ }^{3}$
${ }^{1}$ Faculdade de Ciências Agrárias, Universidade Federal da Grande Dourados, Dourados, MS, Brasil.
${ }^{2}$ Faculdade de Ciências Agronômicas, Universidade Estadual Paulista, Botucatu, SP, Brasil.
${ }^{3}$ Centro de Ciências Agrárias, Universidade Federal de São Carlos, São Carlos, SP, Brasil. *E-mail: paulovsilva@ufgd.edu.br
(Orcid: 0000-0003-0515-3316; 0000-0003-4647-5602; 0000-0001-9237-2992; 0000-0001-6909-8120; \\ 0000-0002-4542-7601; 0000-0001-5433-5373; 0000-0003-3262-2819; 0000-0002-9123-1861)
}

Recebido em 14/02/2021; Aceito em 02/06/2021; Publicado em 14/06/2021.

\begin{abstract}
RESUMO: O controle do capim-amargoso, atualmente tem sido um dos grandes desafios na cultura da soja, e os herbicidas pré-emergentes surgem como opção de manejo. O objetivo desse trabalho foi avaliar o controle do capim-amargoso através de herbicidas pré-emergentes posicionados em diferentes regimes de irrigação e quantidades de palha. Foram realizados dois experimentos o primeiro com palha de milho + Urochloa ruziziensis ( 0 e $3 \mathrm{t} \mathrm{ha}^{-1}$ ) e o segundo com ausência de palha, ambos em casa de vegetação com delineamento experimental inteiramente casualizado em esquema fatorial $6 \times 3$, no primeiro fator regimes de irrigação (inicial de $5 \mathrm{~mm}$ e após 48 horas $10 \mathrm{~mm}$ para manutenção, inicial de $20 \mathrm{~mm}$ e após 48 horas $10 \mathrm{~mm}$ para manutenção, inicial de $5 \mathrm{~mm}$ e após, 5, 10, 15 ou 20 dias uma chuva de $20 \mathrm{~mm})$ e no segundo, os herbicidas pré-emergentes: (diclosulam $\left(29,4\right.$ g.i.a ha $\left.{ }^{-1}\right)$; flumioxazin + imazethapyr $\left(50+106\right.$ g.i.a ha $\left.{ }^{-1}\right)$ e diuron + sulfentrazone $(420+$ 210 g.i.a ha $\left.\mathrm{h}^{-1}\right)$ ). Na aplicação diretamente no solo e sobre palha, o diclosulam apresentou as menores porcentagens de controle em todos os regimes de irrigação com primeira chuva de $5 \mathrm{~mm}$ e segunda de $20 \mathrm{~mm}$. Já diuron + sulfentrazone e flumioxazin + imazethapyr não apresentaram diferenças significativas nos regimes de irrigação controlando de maneira eficaz o capim-amargoso. A eficácia do diclosulam sofreu influência dos intervalos de seca após a aplicação, diuron + sulfentrazone e flumioxazin + imazethapyr apresentaram um controle eficaz do capim-amargoso em todos os tratamentos.
\end{abstract}

Palavras-chave: Digitaria insularis; residual; período de seca.

\section{Water regime and straw influence on the effectiveness of preemerging herbicides without control of sourgrass?}

\begin{abstract}
The control of sourgrass, has been one of the great challenges in the soybean culture, and the pre-emergent herbicides appear as a management option. The objective of this work was to evaluate the control of sourgrass using pre-emergent herbicides positioned under different irrigation regimes and amounts of straw. Two experiments were carried out, the first with corn straw + Urochloa ruziziensis $\left(0\right.$ and $\left.3 \mathrm{tha}^{-1}\right)$ and the second without straw, both in a greenhouse with a completely randomized design in a $6 \times 3$ factorial scheme, in the first factor irrigation regimes (initial of $5 \mathrm{~mm}$ and after 48 hours $10 \mathrm{~mm}$ for maintenance, initial of $20 \mathrm{~mm}$ and after 48 hours $10 \mathrm{~mm}$ for maintenance, initial of $5 \mathrm{~mm}$ and after, 5, 10,15 or 20 days a rain of $20 \mathrm{~mm}$ ) and in the second, the pre-emergent herbicides: (diclosulam $\left(29.4 \mathrm{~g}\right.$ i.a ha $\left.{ }^{-1}\right)$; flumioxazin + imazethapyr $(50+106 \mathrm{~g}$ i.a ha $\left.{ }^{-1}\right)$ and diuron + sulfentrazone $\left(420+210 \mathrm{~g}\right.$ i.a ha $\left.{ }^{-1}\right)$. When applied directly to the soil and on straw, diclosulam showed the lowest percentages of control in all irrigation regimes with the first rain of $5 \mathrm{~mm}$ and the second of $20 \mathrm{~mm}$. Diuron + sulfentrazone and flumioxazin + imazethapyr did not present significant differences in the irrigation regimes, effectively controlling the sourgrass. The effectiveness of diclosulam was influenced by drought intervals after application, diuron + sulfentrazone and flumioxazin + imazethapyr showed an effective control of sourgrass in all treatments.
\end{abstract}

Keywords: Digitaria insularis; residual; dry season.

\section{INTRODUÇÃO}

O capim-amargoso (Digitaria insularis (L.) Fedde) é uma planta daninha da família Poaceae, perene, ereta, que pode atingir até $1 \mathrm{~m}$ de altura, formando touceiras quando se tornam adultas, sua reprodução se dá por duas vias, sexual com produção de sementes, e assexuada com a formação de rizomas curtos (LORENZI et al., 2014). Essa planta é nativa de regiões tropicais e subtropicais do continente americano, ocorrendo desde o sul dos Estados Unidos até o norte da Argentina, sua inflorescência é emitida a partir dos 63 dias após a emergência, suas sementes são pequenas, revestidas por pelos, facilmente levadas pelo vento a longas distâncias e apresentam alto poder germinativo (KISSMANN, 1997; MACHADO et al., 2006).

Capim-amargoso é uma das principais plantas daninhas do nosso país, causando perdas significativas na cultura da 
soja (Glycine max L.), sendo essa a principal cultura de primeira safra no Brasil, ocupando cerca de 38,2 milhões de hectares (Companhia Nacional de Abastecimento -CONAB, 2020).

Segundo Braz et al. (2021), a massa seca da parte aérea da soja diminuiu em resposta ao aumento das densidades de capim amargoso. Sendo que a massa seca da soja diminuiu $55 \%$ sobre infestação de 8 plantas de capim amargoso por $\mathrm{m}^{2}$. Além dos aspectos inerentes a mato-competição, essa planta daninha apresenta relato de biótipos resistentes ao mecanismo de ação EPSPs (5-enol-piruvil-shikimate-3fosfato sintase) (HEAP, 2020), apresentando distribuição geográfica por todo o território brasileiro (LOPEZOVEJERO et al., 2017).

Nesse sentido, para reduzir os casos de biótipos resistentes e/ou promover um controle eficaz é recomendado a rotação de herbicidas com diferentes mecanismos de ação (GAZZIERO et al., 2016). Uma opção é a utilização de herbicidas pré-emergentes, com diferentes mecanismos de ação, tais como inibidores da Protox (Protoporfirina Oxidase), ALS (Acetolactato Sintase) e Fotossistema II (Fotossíntese), visto que, há poucas opções na pós-emergência, sendo frequente o uso de herbicidas inibidores da enzima ACCase (acetil-coenzima-Acarboxilase) (AGROFIT, 2021).

Os herbicidas pré-emergentes promovem o controle no início da germinação e/ou durante o desenvolvimento inicial da planta daninha e através do seu efeito residual proporcionam o controle dos fluxos germinativos durante o período crítico de infestação (PCPI) (ANDRADE, 2019). O capim-amargoso apresenta crescimento inicial lento levando até 35 dias para o início da formação dos rizomas curtos, após esse período essa planta é considerada de difícil controle em pós-emergência (GAZZIERO et al., 2012).

De forma frequente, os herbicidas pré-emergentes são posicionados sobre palha oriunda da cultura anterior, que permanece na superfície do solo após a colheita. Na cultura da soja é frequente o posicionamento sobre palha de milho (Zea mays L.) + Urochloa ruziziensis (R.Germ. \& C.M.Evrard) Crins, especialmente na região do Centro-Oeste, a qual é utilizada no sistema de integração lavoura-pecuária (CASTALDO et al., 2015). O sistema de cultivo milho em consórcio com Urochloa spp. tornou-se um dos mais eficientes sistemas de produção, visando a formação de palhada para o cultivo da soja em áreas de plantio direto. No entanto, a palha se torna uma barreira física para o posicionamento dos herbicidas pré-emergentes, sendo necessário à transposição dos produtos até a solução do solo (SILVA et al., 2020).

Segundo Maciel e Velini, (2005) precipitações de $20 \mathrm{~mm}$ são fundamentais para transpor o herbicida até a solução do solo. No entanto, o período de seca e/ou chuvas inferiores a $20 \mathrm{~mm}$ após a aplicação do herbicida pré-emergente pode promover sua interceptação e adsorção a palha. Assim, no momento que se iniciam as chuvas em quantidades maiores não ocorre a reversibilidade do processo, dessorção, e consequentemente o transporte do herbicida da palha até o solo, reduzindo assim a eficácia desses produtos no controle de plantas daninhas (DA SILVA et al., 2020; CLARK et al., 2019).

Dessa maneira, os herbicidas pré-emergentes precisam apresentar algumas características físico-químicas, como baixo coeficiente de partição octanol-água $\left(\mathrm{K}_{\text {ow }}\right)$, alta solubilidade em água (S) e baixa pressão de vapor $(\mathrm{P})$, os quais são essenciais para que não ocorram processos de adsorção do herbicida na palha, possibilitando o transporte do herbicida pela barreira física composta por esse material vegetal (MATOS et al., 2016). Dentre as opções de herbicidas pré-emergentes que podem ser utilizados na cultura da soja, destacam-se o diclosulam, flumioxazin + imazethapyr e diuron + sulfentrazone (AGROFIT, 2021).

Fatores como regime de irrigação e/ou quantidade de palha podem ocasionar variação na eficácia de controle destes herbicidas. Diante do exposto, é necessária a realização de pesquisas visando o correto posicionamento de herbicidas pré-emergentes em aplicações sobre solo com palha ou sem palha de milho + U. ruziziensis, no intuito de controlar de maneira eficaz as plantas daninhas. Logo, o objetivo desse trabalho foi avaliar o controle do capim-amargoso através de herbicidas pré-emergentes em diferentes regimes de irrigação e quantidades de palhas.

\section{MATERIAL E MÉTODOS}

O experimento foi realizado em casa de vegetação, no período de 14 de janeiro de 2020 até 20 de março de 2020 no município de Dourados, MS, Brasil. Segundo a classificação climática de Koppen, Dourados-MS apresenta o clima tropical, do tipo Am, com pluviosidade média anual de 1428 $\mathrm{mm}$ e temperatura média anual de $22,7^{\circ} \mathrm{C}$ (KÖPPEN; GEIGER, 1928).

As unidades experimentais foram constituídas de vasos de polietileno com capacidade para $4 \mathrm{~L}$ de solo, preenchidos com Latossolo Vermelho Distroférrico (Empresa Brasileira de Pesquisa Agropecuária-EMBRAPA, 2013), de textura argilosa cujas as propriedades físico-químicas encontram-se na (Tabela 1). As amostras de solo foram coletadas em uma área em pousio, na profundidade de $0-20 \mathrm{~cm}$ e foram peneiradas para remoção dos resíduos presentes na superfície do solo, posteriormente secas ao ar e acondicionadas nas unidades experimentais.

Foram realizados dois experimentos o primeiro com palha de milho $+U$. ruziziensis $\left(3 \mathrm{t} \mathrm{ha}^{-1}\right)$ e o segundo com ausência de palha $\left(0 \mathrm{t} \mathrm{ha}^{-1}\right)$, ambos em casa de vegetação. $\mathrm{O}$ delineamento experimental adotado foi inteiramente casualizado, organizado no esquema fatorial $6 \times 3$, no primeiro fator os seis regimes de irrigação (1- chuva inicial de $5 \mathrm{~mm}$ e após 48 horas inicia-se o manejo diário de $10 \mathrm{~mm}$; 2- chuva inicial de $20 \mathrm{~mm}$ após 48 horas inicia-se o manejo diário de $10 \mathrm{~mm}$; 3- chuva inicial de $5 \mathrm{~mm}$ após 5 dias uma segunda chuva de $20 \mathrm{~mm}$; 4- chuva inicial de $5 \mathrm{~mm}$ após 10 dias uma segunda chuva de $20 \mathrm{~mm}$; 5 - chuva inicial de $5 \mathrm{~mm}$ após 15 dias uma segunda chuva de $20 \mathrm{~mm}$ e 6 - chuva inicial de $5 \mathrm{~mm}$ após 20 dias uma segunda chuva de $20 \mathrm{~mm}$ ) e no segundo os herbicidas pré-emergentes (diclosulam; flumioxazin + imazethapyr e diuron + sulfentrazone).

Tabela 1. Análise química do solo utilizado nas unidades experimentais. Dourados - MS, Brasil.

Table 1. Chemical analysis of the soil used in the experimental units. Dourados - MS, Brazil.

\begin{tabular}{ccccccccccccc}
\hline & $\mathrm{Al}$ & $\mathrm{H}+\mathrm{Al}$ & $\mathrm{P}(\mathrm{mehl})$ & $\mathrm{K}$ & $\mathrm{Ca}$ & $\mathrm{Mg}$ & $\mathrm{SB}$ & $\mathrm{CTC}$ & $\mathrm{V}$ & Areia & Silte & Argila \\
\hline 5,7 & 0,00 & 2,87 & 9,0 & 362 & 5,13 & 1,60 & 7,66 & 10,53 & 72,74 & 192 & 165 & 643 \\
\hline
\end{tabular}

Unidades: Al, H+Al, Ca, Mg, SB e CTC (cmolc dm-3); K, P (rmehl) (mg dm-3); V (\%). 
A semeadura do capim-amargoso foi realizada na profundidade de $2 \mathrm{~cm}$, com quantidade de sementes suficiente para se obter uma população final de aproximadamente 10 plantas daninhas por unidade experimental. Foi utilizada uma quantidade de $0,1 \mathrm{~g}$ de sementes em cada unidade experimental, que foi determinada através de um teste de germinação conforme a regra de análise de sementes (RAS, 2009) com 4 repetições, onde se obteve uma média de 11,25 plantas por unidade experimental, se aproximando da quantidade desejada.

No experimento 1 com utilização de palha, sendo que a palha utilizada foi retirada do campo, em uma área de consórcio milho $+U$. ruzizienses. $\mathrm{O}$ milho foi semeado no espaçamento $0,90 \mathrm{~m}$ e a $U$. ružizienses no espaçamento de 0,40 $\mathrm{m}$ na data de 15 de março de 2019. Em 23 de outubro de 2019, antes da dessecação da área para o plantio da safra 2019/20, a palha remanescente no campo foi coletada e acondicionada em sacos plásticos, levada para o laboratório, para posterior homogeneização, fragmentação e pesagem. Nesse mesmo dia, utilizou-se um quadrado com área de $1 \mathrm{~m}^{2}$, para determinação da quantidade de palha por hectare, sendo determinado $3 \mathrm{t} \mathrm{ha}^{-1}$. Para o experimento com palha, as $3 \mathrm{t}$ $\mathrm{ha}^{-1}$ foram determinadas através de uma correlação da área da superfície da unidade experimental (vaso de polietileno com $20 \mathrm{~cm}$ de diâmetro), sendo determinada com a quantidade de palha verificada em campo, o valor de 9,42 g que foi a quantidade de palha alocada na área da unidade experimental e representa $3 \mathrm{t} \mathrm{ha}^{-1}$. No segundo experimento se adotou $0 \mathrm{t}$ $\mathrm{ha}^{-1}$ (sem palha). Após a semeadura do capim-amargoso, para o experimento com palha, foram depositadas na superfície do solo a quantidade mencionada acima.

Em seguida, foram aplicados os herbicidas préemergentes diclosulam (29,4 g.i.a ha- $\left.{ }^{1}\right)$; flumioxazin + imazethapyr $\left(50+106\right.$ g.i.a ha $\left.{ }^{-1}\right)$ e diuron + sulfentrazone $(420+210$ g.i.a ha-1), exceto nas testemunhas, as quais não receberam a aplicação dos herbicidas pré-emergentes. Para aplicação dos herbicidas, foi utilizado um pulverizador costal de pressão constante, pressurizado por $\mathrm{CO}_{2}$, com pontas do tipo AI 110.015, pressão de 3,0 $\mathrm{kgf} \mathrm{cm}^{-2}$, com volume de calda de $170 \mathrm{~L} \mathrm{ha}^{-1}$. No momento da aplicação dos herbicidas foram aferidas as condições ambientais, sendo a temperatura de $35^{\circ} \mathrm{C}$, umidade de $55,5 \%$ e velocidade do vento de $1,5 \mathrm{~m}$ $\mathrm{s}^{-1}$.

Após a pulverização, foram realizadas as simulações de chuva por meio de um simulador de chuva com vazão de $1 \mathrm{~L}$ $\min ^{-1}$. As simulações de chuva nos sistemas de irrigação (que representou o primeiro fator da interação fatorial) os quais foram combinados com o fator B da interação fatorial dos herbicidas (diclosulam; flumioxazin + imazethapyr e diuron + sulfentrazone) apresentaram variações de acordo com os regimes de irrigação adotados. No tratamento 1 chuva inicial de $5 \mathrm{~mm}$ e após 48 horas iniciou-se o manejo diário de $10 \mathrm{~mm} ; 2$ chuva inicial de $20 \mathrm{~mm}$ após 48 horas iniciou-se o manejo diário de $10 \mathrm{~mm}$; 3- chuva inicial de 5 $\mathrm{mm}$ após 5 dias uma segunda chuva de $20 \mathrm{~mm}$; 4- chuva inicial de $5 \mathrm{~mm}$ após 10 dias uma segunda chuva de $20 \mathrm{~mm}$; 5- chuva inicial de $5 \mathrm{~mm}$ após 15 dias uma segunda chuva de $20 \mathrm{~mm}$ e 6 - chuva inicial de $5 \mathrm{~mm}$ após 20 dias uma segunda chuva de $20 \mathrm{~mm}$, como ilustrado na (Tabela 2). Após 48 horas da segunda simulação de chuva dos tratamentos 3 ao 6 se iniciou a irrigação diária de $10 \mathrm{~mm}$ para manutenção das plantas daninhas até o termino do experimento.
Tabela 2. Simulação de chuva e manejo de irrigação. Table 2. Rain simulation and irrigation management.

\begin{tabular}{ccccc}
\hline $\begin{array}{c}\text { Regime de } \\
\text { irrigação }\end{array}$ & $\begin{array}{c}\text { Intervalos entre } \\
1^{\text {a e }} \text { 2 " chuva" }\end{array}$ & $\begin{array}{c}1 \\
\text { Aplicação }\end{array}$ & $\begin{array}{c}2 \\
\text { Aplicação }\end{array}$ & $\begin{array}{c}\text { Manejo } \\
\text { diário }\end{array}$ \\
\hline 1 & --- & $5 \mathrm{~mm}$ & --- & $10 \mathrm{~mm}$ \\
2 & --- & $20 \mathrm{~mm}$ & --- & $10 \mathrm{~mm}$ \\
3 & 5 dias & $5 \mathrm{~mm}$ & $20 \mathrm{~mm}$ & $10 \mathrm{~mm}$ \\
4 & 10 dias & $5 \mathrm{~mm}$ & $20 \mathrm{~mm}$ & $10 \mathrm{~mm}$ \\
5 & 15 dias & $5 \mathrm{~mm}$ & $20 \mathrm{~mm}$ & $10 \mathrm{~mm}$ \\
6 & 20 dias & $5 \mathrm{~mm}$ & $20 \mathrm{~mm}$ & $10 \mathrm{~mm}$ \\
\hline
\end{tabular}

O controle das plantas daninhas foi avaliado aos 42 dias após a emergência (DAE) das plantas daninhas, por meio de uma escala percentual de notas em que 0 (zero) corresponde a nenhuma injúria na planta e 100 (cem) à morte das plantas, seguindo a metodologia proposta pela Asociation Latinoamericana de Malezas-ALAM (1974). Aos 42 DAE, as plantas remanescentes nas unidades experimentais foram cortadas rente ao solo, contadas e acondicionadas em sacos de papel, sendo levadas a estufa de circulação forçada de ar $60^{\circ} \mathrm{C}$ por 72 horas, determinando-se assim a massa seca da parte aérea.

Os resultados referentes ao controle do capim-amargoso foram submetidos à análise de variância pelo teste $\mathrm{F}$ e as médias dos tratamentos foram comparadas pelo teste de Tukey. Os dados oriundos da massa seca foram transformados em porcentagem de redução em virtude dos diferentes tratamentos em comparação com a testemunha. $\mathrm{O}$ programa computacional de estatística utilizado foi o Agroestat (Barbosa; Maldonato, 2009) e quando as médias foram significativas foram elaborados gráficos no sigmaplot.

\section{RESULTADOS}

No desdobramento do fator irrigação, para o experimento 1 - sem palha, para o controle do capimamargoso foi possível observar maiores porcentagens de controle nos regimes de irrigação 1,2 e 3, com médias de $95,16 \%, 98,41 \%$ e $93,00 \%$ respectivamente, e o menor controle foi verificado no regime de irrigação $6 \mathrm{com} 85,50 \%$. No entanto, todos os regimes de irrigação estudados apresentaram porcentagens de controle superiores a $80 \%$. Para a redução de massa seca não houve diferença significativa (Tabela 3).

Tabela 3. Desdobramento do fator regime de irrigação para o controle do capim-amargoso e redução de massa seca no experimento 1 - sem palha.

Table 3. Unfolding of the irrigation regime factor for the control of sourgrass and reduction of dry mass in experiment 1 - without straw.

\begin{tabular}{ccc}
\hline $\begin{array}{c}\text { Regime de } \\
\text { Irrigação }\end{array}$ & Controle $(\%)$ & $\begin{array}{c}\text { Redução de Massa Seca } \\
(\%)\end{array}$ \\
\hline 1 & $95,16 \mathrm{ab}$ & $98,33 \mathrm{a}$ \\
2 & $98,41 \mathrm{a}$ & $98,16 \mathrm{a}$ \\
3 & $93,00 \mathrm{abc}$ & $96,73 \mathrm{a}$ \\
4 & $89,16 \mathrm{bc}$ & $94,58 \mathrm{a}$ \\
5 & $87,41 \mathrm{bc}$ & $90,31 \mathrm{a}$ \\
6 & $85,50 \mathrm{c}$ & $81,99 \mathrm{a}$ \\
\hline DMS $(5 \%)$ & 7,97 & 8,15 \\
\hline F & $6,68^{* *}$ & $10,46^{\text {ns }}$ \\
\hline C.V. $(\%)$ & 7,22 & 7,37
\end{tabular}

** Significativo ao nível de $1 \%$ de probabilidade pelo teste F; C.V. Coeficiente de variação; DMS - Diferença mínima significativa a 5\%. Médias seguidas por letras iguais não diferem entre si pelo teste de Tukey a $5 \%$ de significância. 
Para o desmembramento do fator herbicida para o experimento 1 - sem palha, a maior porcentagem de controle foi observada nos tratamentos diuron + sulfentrazone $96,50 \%$, seguido de flumioxazin + imazethapyr $91,29 \%$, e o menor com o diclosulam com $86,54 \%$. O diclosulam também apresentou menor redução de massa seca com 89,21\% (Tabela 4).

Tabela 4. Desdobramento do fator pré-emergente para o controle do capim-amargoso e redução de massa seca no experimento 1 sem palha

Table 4. Unfolding of the pre-emergent factor for the control of sourgrass and reduction of dry mass in experiment 1 - without straw.

\begin{tabular}{lcc}
\hline \multicolumn{1}{c}{ Herbicidas } & $\begin{array}{c}\text { Controle } \\
(\%)\end{array}$ & $\begin{array}{c}\text { Redução de } \\
\text { Massa Seca (\%) }\end{array}$ \\
\hline Diclosulam & $86,54 \mathrm{c}$ & $89,21 \mathrm{~b}$ \\
Diuron + Sulfentrazone & $96,50 \mathrm{a}$ & $95,89 \mathrm{a}$ \\
Flumioxazin + Imazethapyr & $91,29 \mathrm{~b}$ & $94,60 \mathrm{a}$ \\
\hline DMS (5\%) & 4,59 & 4,82 \\
F & $13,63^{* *}$ & $4,82^{* *}$ \\
C.V. $(\%)$ & 7,22 & 7,37 \\
\hline
\end{tabular}

** Significativo ao nível de $1 \%$ de probabilidade pelo teste F; C.V. Coeficiente de variação; DMS - Diferença mínima significativa a 5\%. Médias seguidas por letras iguais não diferem entre si pelo teste de Tukey a $5 \%$ de significância.

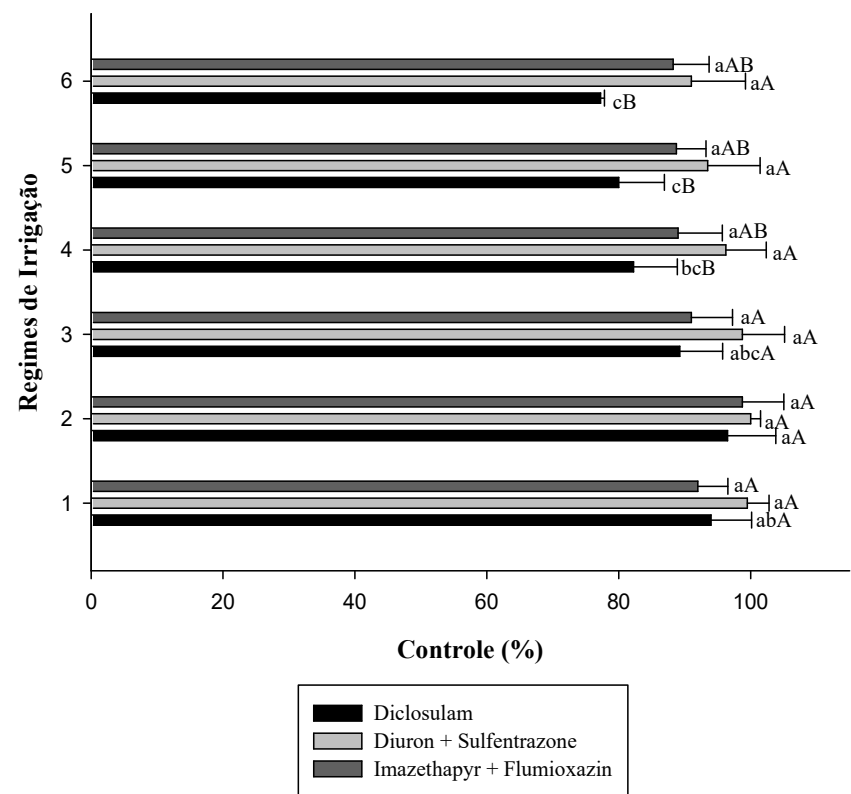

$\mathrm{Na}$ interação fatorial o diclosulam resultou nas menores porcentagens de controle do capim-amargoso quando submetido os regimes de irrigação 3, 4, 5 e 6 respectivamente $89,29 \%, 82,25 \%, 80 \%$ e $77,25 \%$ que não diferiram significativamente entre si, mas apresentaram diferenças significativas em relação aos tratamentos 1 (94\%) e 2 $(96,50 \%)$. Os demais herbicidas testados, diuron + sulfentrazone e flumioxazin + imazethapyr não apresentaram diferenças significativa em relação aos regimes de irrigação (Figura 1).

$\mathrm{Na}$ interação fatorial o diclosulam apresentou as menores porcentagens de controle nos regimes de irrigação 4, 5 e 6 com respectivamente $82,25 \%, 80 \%$ e $77,25 \%$ (Figura 1). $\mathrm{Na}$ redução de massa seca, o diclosulam obteve menor porcentagem no regime de irrigação 6 e os demais préemergentes estudados não apresentaram diferenças significativas em nenhum dos regimes estudados (Figura 1).

No experimento 2, no controle do capim-amargoso através do posicionamento de herbicidas sobre $3 \mathrm{t} \mathrm{ha}^{-1}$ de palha (milho $+U$. ruqiziensis), foi possível observar que os maiores controles foram obtidos na simulação dos regimes de irrigação 1, 2 e 3, com controles de 92,25\%, 95,25\% e $91,91 \%$ respectivamente, ao passo que e o menor controle foi observado no regime de irrigação 6 com 80,33\% (Tabela $5)$.

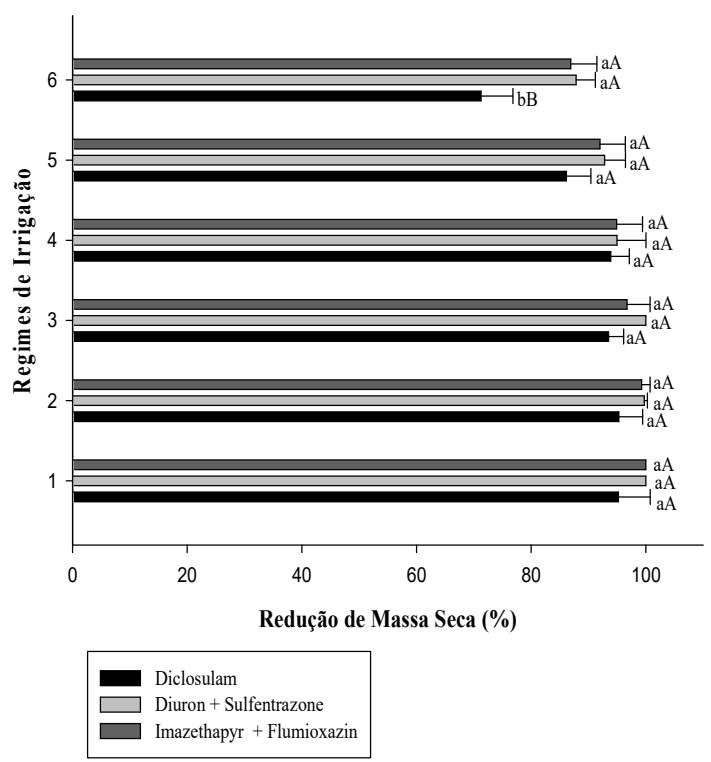

Significativo ao nível de 1\% de probabilidade pelo teste F. Médias seguidas por letras iguais, minúsculas comparam os regimes de irrigação e maiúsculas comparam os pré-emergentes.

Figura 1. Interação entre o fator regime de irrigação e o fator pré-emergente, no experimento 1 - sem palha para o controle e redução de massa seca do capim-amargoso

Figure 1. Interaction between the irrigation regime factor and the pre-emergent factor, in experiment 1 - without straw for the control and reduction of dry mass of sourgrass.

$\mathrm{Na}$ redução de massa seca, para o posicionamento sobre $3 \mathrm{t} \mathrm{ha}^{-1}$ de palha (milho $+U$. ruqiziensis), as maiores porcentagens de controle foram obtidos nos regimes de irrigação 1, 2 e 3, com redução de massa seca de $92,99 \%$, $97,86 \%$ e $95,00 \%$ respectivamente, já a menor redução de massa seca foi observada no regime de irrigação $6 \mathrm{com}$ $82,17 \%$ (Tabela 5).

Para o desdobramento do fator herbicida no experiemento 2, em aplicações sobre $3 \mathrm{t} \mathrm{ha}^{-1}$ de palha (milho $+U$. ruziziensis), as maiores porcentagens de controle do capim-amargoso foram observadas mediante a aplicação de diuron + sulfentrazone e flumioxazin + imazethapyr com respectivamente $93,58 \%$ e $89,54 \%$, e o menor controle foi observado com a utilização do diclosulam com $84,37 \%$. Na redução de massa seca, no experiemnto 2 , os resultados seguiram o mesmo comportamento, as maiores porcentagens foram observadas para diuron + sulfentrazone e flumioxazin + imazethapyr com respectivamente $93,71 \%$ e $91,89 \%$, e a menor porcentagem com a utilização do diclosulam $86,86 \%$ (Tabela 6). 
Tabela 5. Desdobramento do fator regime de irrigação para o controle do capim-amargoso e redução de massa seca no experimento 2 -com $3 \mathrm{t} \mathrm{ha}^{-1}$ de palha de milho $+U$. ruziziensis.

Table 5. Unfolding of the irrigation regime factor for sourgrass control and dry matter reduction in experiment 2 - with $3 \mathrm{t} \mathrm{ha}^{-1}$ of corn straw $+U$. ruziziensis.

\begin{tabular}{ccc}
\hline $\begin{array}{c}\text { Regimes de } \\
\text { Irrigação }\end{array}$ & $\begin{array}{c}\text { Controle } \\
(\%)\end{array}$ & $\begin{array}{c}\text { Redução de Massa Seca } \\
(\%)\end{array}$ \\
\hline 1 & $92,25 \mathrm{a}$ & $92,99 \mathrm{a}$ \\
2 & $95,25 \mathrm{a}$ & $97,86 \mathrm{a}$ \\
3 & $91,91 \mathrm{a}$ & $95,00 \mathrm{a}$ \\
4 & $89,33 \mathrm{ab}$ & $91,76 \mathrm{ab}$ \\
5 & $85,91 \mathrm{ab}$ & $85,13 \mathrm{bc}$ \\
6 & $80,33 \mathrm{~b}$ & $82,17 \mathrm{c}$ \\
\hline DMS $(5 \%)$ & 11,24 & 7,83 \\
F & $3,94^{* *}$ & $10,23^{* *}$ \\
C.V. $(\%)$ & 9,23 & 7,15 \\
\hline
\end{tabular}

** Significativo ao nível de $1 \%$ de probabilidade pelo teste F; C.V. Coeficiente de variação; DMS - Diferença mínima significativa a 5\%. Médias seguidas por letras iguais não diferem entre si pelo teste de Tukey a 5\% de significância.

$\mathrm{Na}$ interação entre os fatores regimes de irrigação e os herbicidas pré-emergentes, foi observado que todos os herbicidas estudados apresentaram controle superior numericamente no regime de irrigação 2 de $92,75 \%$ e inferior no regime de irrigação 6 , onde o diclosulam apresentou 0 menor controle com $70,50 \%$, sendo inferior aos demais

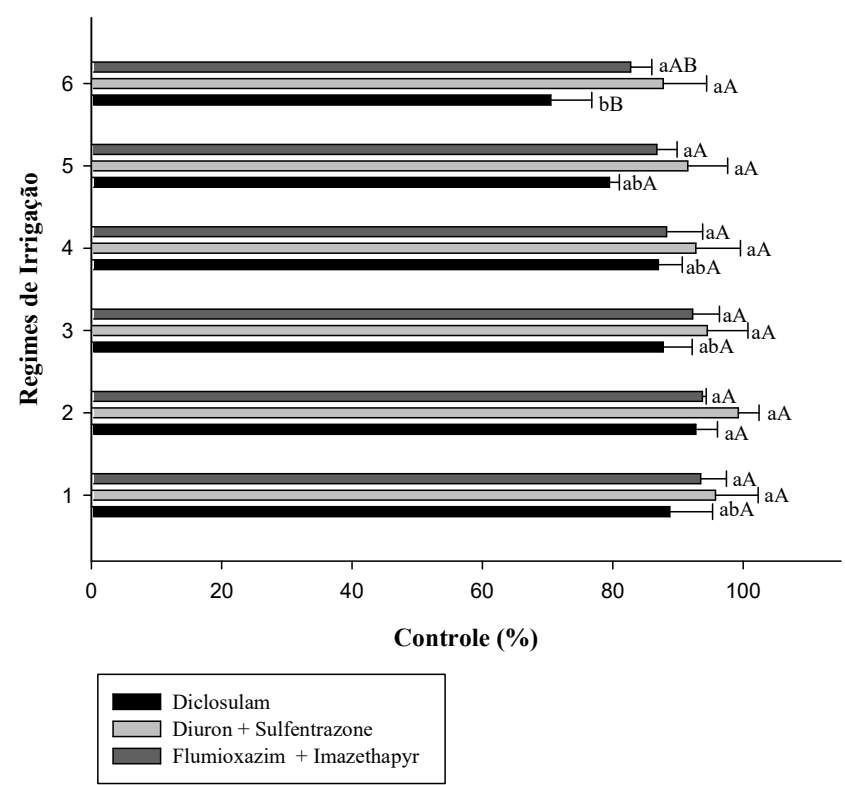

Tabela 6. Desdobramento do fator pré-emergente para o controle do capim-amargoso e redução de massa seca no experimento 2 com 3 t ha $^{-1}$ de palha de milho + U. ruigiziensis.

Table 6. Unfolding of the pre-emergent factor for the control of sourgrass and reduction of dry mass in experiment 2 - with 3 t ha ${ }^{1}$ of straw of corn $+U$. ruziziensis.

\begin{tabular}{ccc}
\hline \multicolumn{1}{c}{ Herbicidas } & $\begin{array}{c}\text { Controle } \\
(\%)\end{array}$ & $\begin{array}{c}\text { Redução de } \\
\text { Massa Seca }(\%)\end{array}$ \\
\hline Diclosulam & $84,37 \mathrm{~b}$ & $86,86 \mathrm{~b}$ \\
Diuron + Sulfentrazone & $93,58 \mathrm{a}$ & $93,71 \mathrm{a}$ \\
Flumioxazin + Imazethapyr & $89,54 \mathrm{a}$ & $91,89 \mathrm{a}$ \\
\hline DMS (5\%) & 6,48 & 4,51 \\
F & $5,88^{* *}$ & 7,16 \\
C.V. $(\%)$ & 9,23 & 7,15 \\
\hline
\end{tabular}

** Significativo ao nível de 1\% de probabilidade pelo teste F; C.V. Coeficiente de variação; DMS - Diferença mínima significativa a 5\%. Médias seguidas por letras iguais não diferem entre si pelo teste de Tukey a 5\% de significância.

herbicidas (Figura 2). Na redução de massa seca, o dicloulam apresentou a menor porcentagem nos regimes de irrigação 5 e 6, os demais herbicidas pré-emergentes dentro dos regimes de irrigação não apresentaram diferença significativa (Figuras 2).

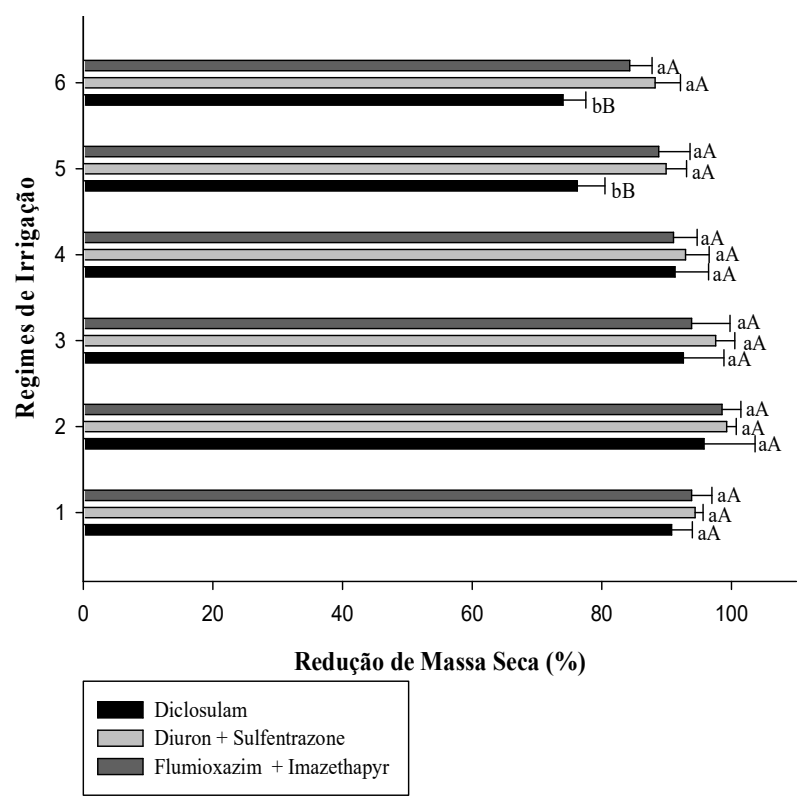

Significativo ao nível de 1\% de probabilidade pelo teste F. Médias seguidas por letras iguais, minúsculas comparam os regimes de irrigação e maiúsculas comparam os pré-emergentes.

Figura 2. Interação entre o fator regime de irrigação e o fator pré-emergente, no experimento $2-\mathrm{com}^{3} \mathrm{t}$ ha-1 de palha de milho $+U$. ruziziziensis para o controle e redução de massa seca do capim-amargoso

Figure 2. Interaction between the irrigation regime factor and the pre-emergent factor, in experiment $2-$ with $3 \mathrm{t}$ ha ${ }^{-1}$ of corn straw $+U$. ruriziensis for the control and reduction of dry mass of sourgrass.

\section{DISCUSSÃO}

Os herbicidas pré-emergentes (diclosulam, diuron + sulfentrazone e flumioxazin + imazethapyr) que receberam uma chuva inicial de $20 \mathrm{~mm}$, logo após a sua aplicação, ou seja, sem intervalos de tempo, apresentaram elevado controle do capim-amargoso, tanto no posicionamento sobre $3 \mathrm{t} \mathrm{ha}^{-1}$ de palha de milho + U. ruziziensis quanto diretamente no solo. Desse modo, essa quantidade chuva foi suficiente para proporcionar o transporte dos herbicidas da palha e/ou superfície do solo até a faixa que as sementes de plantas daninhas foram semeadas, e também foi suficiente para disponibilizar esses produtos na solução do solo, resultando em uma porcentagem de controle em índices aceitáveis.

Esses resultados podem ser associados as características físico-químicas, pois os produtos formulados utilizados no presente experimento diclosulam, diuron + sulfentrazone e flumioxazin + imazethapyr, são classificados como produtos de alta solubilidade ou solubilidade media (AGROFIT, 
2021). Dessa forma, a chuva de $20 \mathrm{~mm}$, simulada imediatamente após a aplicação resultou em menor tempo de interação dos herbicidas com as superfícies do solo (minerais de argila e matéria orgânica) e palha, resultando em menor tempo para adsorção. Além disso, a chuva de $20 \mathrm{~mm}$ foi suficiente para favorecer o transporte dos herbicidas através da palha e a lixiviação no perfil do solo, contribuindo para o posicionamento e incorporação dos produtos na faixa de semeadura, o que contribui para um excelente controle do capim-amargoso.

Já as chuvas inicias de $5 \mathrm{~mm}$, com intervalo de tempo para segunda chuva,não foram suficientes para promover $\mathrm{o}$ transporte do herbicida da palha e/ou superfície do solo, para zona de semeadura das sementes do capim-amargoso, ou seja, não foi eficaz na incorporação do produto. Nessa situação os produtos ficaram disponíveis a perdas por degradação e/ou transformação além de apresentarem maior dificuldade de reversibilidade do processo de adsorção e/ou recuperação do herbicida interceptado pela palha. Nessa situação mesmo após a ocorrência de uma segunda chuva de $20 \mathrm{~mm}$, observou-se redução da eficácia do diclosulam quando comprado com a simulação de chuva de $20 \mathrm{~mm}$ imediatamente após a aplicação dos produtos.

Para a maioria dos herbicidas, solos com boas condições de umidade promovem tanto a ação como a dissipação mais rápida, por meio, por exemplo de raios ultravioletas e infravermelhos (MONQUERO et al., 2013). A solubilidade do diclosulam em água é dependente do $\mathrm{pH}$ e varia de $\sim 100$ $\mathrm{mg} \mathrm{kg}-1$ em pH entre 5 e 7 e $>4.000 \mathrm{mg} \mathrm{kg}^{-1}$ em pH 9 (LAVORENTI et al., 2003). Dessa forma, a chuva inicial de $5 \mathrm{~mm}$, pode não ter sido suficiente para disponibilizar o produto em solução do solo para um controle efetivo das plantas daninhas, e a permanência desse herbicida (no solo e/ou superficie do solo), possibilitou o início da fotodegradação diminuído a disponibilidade do produto em solução do solo no momento da ocorrência da segunda chuva.

Segundo Silva et al. (2007), conforme aumenta o período de seca após a aplicação dos herbicidas, os mesmos sofrem processos de fotodegradação, volatilização, degradação química, biológica e sorção, ocasionando assim, menor controle de plantas daninhas. Nesse contexto, os herbicidas estudados nesse trabalho mostraram-se mais suscetíveis aos processos de sorção na palha e no solo. Entretanto, pode ocorrer o processo inverso (dessorção), se uma segunda chuva com maior intensidade $(20 \mathrm{~mm})$ ocorrer em tempo hábil, isso tornaria parte do herbicida disponível na solução do solo, resultando em controle. No entanto, quanto maior a quantidade de argila, matéria orgânica dos solos e/ou a quantidade de palha presente na superfície do solo, possivelmente maior será a dificuldade de dessorção e/ou será necessário uma maior quantidade de chuva para que ocorra a dessorção, desses herbicidas, e consequentemente o transporte até a solução do solo (CHRISTOFFOLETI et al., 2008; OLIVEIRA; BRIGHENTI, 2011).

Monquero et al. (2013) realizando experimento em casa de vegetação, utilizando um Latossolo Vermelho distroférrico detextura argilosa, para massa seca do girassol, no tratamento que foi aplicado diclosulam $\left(35 \mathrm{~g} \mathrm{ha}^{-1}\right)$ no dia da semeadura, as maiores porcentagens de redução de massa seca ocorreram nos tratamentos com $100 \%$ da capacidade de campo do solo e as menores com $60 \%$ da capacidade de campo.
Os regimes de irrigação resultaram em menor influência na eficácia dos herbicidas diuron + sulfentrazone e flumioxazin + imazethapyr, pois em nenhuma situação, para esses herbicidas o controle do capim-amargoso foi inferior a $80 \%$. No entanto ressalta-se que durante todo o experimento o solo foi mantido úmido. Grigolli e Grigolli, (2019), em contrapartida encontraram resultados diferentes, avaliando a eficácia de controle do capim-amargoso através de diferentes herbicidas pré-emergentes, obtiveram controle de 62,5, 81,2 e $74,4 \%$ através dos herbicidas diclosulam (35 g.ia.ha- ${ }^{-1}$ ), flumioxazin + imazethapyr $\left(50+100\right.$ g.ia.ha $\left.^{-1}\right)$ e diuron + sulfentrazone $\left(420+210\right.$ g.ia.ha $\left.{ }^{-1}\right)$, aos 35 dias após a aplicação dos tratamentos em solo de textura mista.

Já o herbicida diclosulam foi o mais afetado pelos períodos de seca após a aplicação, principalmente quando posicionado sobre palha. Segundo Negrisioli (2005) os resíduos vegetais apresentam maior capacidade de adsorção dos herbicidas do que o solo, pela sua alta constituição de lipídeos. O diclosulam apresentou redução de eficácia quanto maior o tempo de espera do produto posicionado sobre o solo ou palha, até a ocorrência da chuva de $20 \mathrm{~mm}$. Logo, quanto maior o tempo que o produto ficou vulnerável para os processos de degradação e/ou transformação, maiores foram às reduções de eficácia de controle.

Nas conduções dos experimentos um ponto a ser considerado é que embora não tenha se realizado a interação fatorial entre as aplicações sobre palha e diretamente no solo, e optado por se realizar dois experiemntos distintos, se observou uma menor eficácia de controle dos herbicidas estudados nas aplicações sobre $3 \mathrm{t} \mathrm{ha}^{-1}$ de palha de milho + U. ruriziensis, destacando o diclosulam com menor controle. Da Silva et al. (2020), relataram que $3 \mathrm{tha}^{-1}$ de palha de milho + U. ruziziensis, resultam em uma cobertura de $82,5 \%$ do solo, funcionando como uma barreira física para herbicidas, que no caso do flumioxazin necessitou de uma chuva de $40 \mathrm{~mm}$ para promover o controle eficaz de amendoim-bravo (Euphorbia heterophylla L.).

Resultados semelhantes foram obtidos por Carbonari et al. (2008), os quais observaram elevados níveis de controle de corda-de-viola (Ipomoea grandifolia Danner) e guanxuma (Sida rhombifolia L.), através do herbicida diclosulam (25,2 g i.a. ha$\left.{ }^{1}\right)$, exceto para a aplicação em palha seca e úmida de sorgo (Sorghum bicolor (L.) Moench) sem ocorrência de chuvas, demostrando assim, a necessidade da irrigação ou chuvas após a aplicação. Os autores ainda enfatizam que a retenção de herbicidas sobre palha, os submete a condições de fotodegradação e volatilização até que seja levado ao solo pela chuva.

A associação de diferentes ingredientes ativos quando comparados ao diclosulam que apresenta um único mecanismo de ação, apresentou maiores porcentagens de controle. Esse comportamento se deve a associação de características físico-químicas oriundas dos diferentes ingredientes ativos e mecanismos de ação, possibilitando assim, a atuação em dois sítios da planta daninha. Dessa forma, o diuron + sulfentrazone em seguida, a flumioxazin + imazethapyr (RODRIGUES; ALMEIDA, 2018).

Coradin et al. (2019) obtiveram resultados semelhantes aos observados no presente trabalho, pelo qual, desenvolveram experimento em casa de vegetação, com diclosulam $\left(25,2 \mathrm{~g} \mathrm{ha}^{-1}\right)$ e flumioxazin + imazethapyr $(106+$ $50 \mathrm{~g} \mathrm{ha}^{-1}$ ), aplicado em solo sem a presença de palha, constatando que a melhor alternativa para o controle do capim-amargoso foi a associação entre flumioxazin + 
imazethapyr que promoveu $96,3 \%$ de controle em comparação ao diclosulam com $71,3 \%$ de controle aos 28 dias após a emergência da planta daninha.

Takano et al. (2017) obtiveram resultados semelhantes aos observados no presente trabalho em relação aos herbicidas pré-emergentes, pelo qual, estudaram o controle do capim-pé-de-galinha (Eleusine indica (L.) Gaertn) que pertence a mesma família do capim-amargoso, em experimento em casa de vegetação testando herbicidas préemergentes, entre eles, o sulfentrazone (600 g i.a ha $\left.{ }^{-1}\right)$, diuron (2000 g i.a ha $\left.{ }^{-1}\right)$, flumioxazin + imazethapyr $(106+50$ $\mathrm{g}$ i.a ha $\left.{ }^{-1}\right)$ e diclosulam (25 g i.a ha $\left.{ }^{-1}\right)$, constando maior controle do capim-pé-de-galinha respectivamente para sulfentrazone $(97,0 \%)$, diuron $(79,3 \%)$, flumioxazin + imazethapyr $(78,0 \%)$ e diclosulam $(41,3 \%)$.

Dessa forma fica evidente que o regime de irrigação, a distribuição e momento de ocorrência de chuva após a aplicação dos herbicidas afetam na eficácia dos herbicidas diclosulam; flumioxazin + imazethapyr e diuron + sulfentrazone no controle de plantas daninhas, e a redução de eficácia pode ser ainda maior quando o posicionamento ocorre sobre palha oriunda da cultura anterior. Assim, com o objetivo da maior eficácia dos herbicidas no controle de plantas daninhas, faz-se necessário a correlação das características físico-químicas dos herbicidas com o regime hídrico e aspectos inerentes ao sistema produtivo.

\section{CONCLUSÕES}

O herbicida diclosulam sofre influência dos intervalos de seca após a aplicação, sendo que apresenta menores controles do capim-amargoso e redução de massa seca para os regimes de irrigação com maiores períodos de seca, tanto para a condição de presença de palha como na ausência de palha. Os herbicidas diuron + sulfentrazone e flumioxazin + imazethapyr não apresentaram diferenças significativas nos regimes de irrigaçãoapresentando um controle eficiente do capim-amargoso, tanto com palha como sem palha.

\section{REFERÊNCIAS}

ALVARES, C. A.; STAPE, J.L.; SENTELHAS, P. C. GONÇALVES, J. L. M.; SPAROVEK, G. Köppen's climate classification map for Brazil. Meteorologische Zeitschrift, v. 22, n. 6, p. 711-728, 2013. DOI: https://doi.org/10.1127/0941-2948/2013/0507

ASOCIATION LATINOAMERICANA DE MALEZAS. Recomendaciones sobre unificación de los sistemas de evaluación em ensayos de control de malezas. ALAM, Bogotá, v. 1, p. 35-38, 1974.

BARBOSA, J. C.; MALDONADO JUNIOR, W. AgroEstat - Sistema para Análises Estatísticas de Ensaios Agronômicos. Jaboticabal: FCAV/UNESP. 2015. 396p. BRAZ, G. B. P.; CRUVINEL, A. G.; CANEPPELE, A. B.; TAKANO, H. K.; SILVA, A. G.; OLIVEIRA JÚNIOR, R. S. Sourgrass Interference On Soybean Grown In Brazilian Cerrado. Revista Caatinga, v. 34, n. 2, p. 350358, 2021. DOI: 10.1590/1983-21252021v34n211rc

CARBONARI, C. A.; MESCHEDE, D. K.; CORREA, M. R.; VELINI, E. D.; TOFOLI, G. R. Eficácia do herbicida diclosulam em associação com a palha de sorgo no controle de Ipomoea grandifolia e Sida rhombifolia. Planta Daninha, Viçosa, v. 26, n. 3, p. 657-664, 2008. DOI: https://doi.org/10.1590/S0100-83582008000300022
CASTALDO, J. H.; NOLLA, A.; MOTA NETO, L. V.; CARNEIRO, A. R.; ROSSA, A. P. Milho e brachiaria consorciados no sistema integração lavoura-pecuária. Journal of Agronomic Sciences, Umuarama, v. 4, n. especial, p. 375-388, 2015. DOI: http://www.dca.uem.br/V4NE/25.pdf

CHRISTOFFOLETI, P. J.; OVEJERO, R. F. L.; DAMIN, V.; DE CARVALHO, S. J. P.; NICOLAI, M. Comportamento dos herbicidas aplicados ao solo na cultura da cana-de-açúcar. 1 ed. Piracicaba: BASF S. A., 2008. p. 9-36.

CLARK, S. L.; DA SILVA, P. V.; DAYAN, F. E.; NISSEN, S. J.; SEBASTIAN, D. J. The Influence of Winter Annual Grass Litter on Herbicide Availability. Weed Science, v. 67, p. 702-709, 2019. DOI: https://doi.org/10.1017/wsc.2019.45

CONAB_Companhia Nacional de Abastecimento. Acompanhamento da safra brasileira: grãos safra 2020/21, $3^{\circ}$ levantamento (2020). Disponível em: <https://www.conab.gov.br/component/k2/item/dow nload/34779_9ec59c49528b037aadde144a7af2743f> Acesso em: 10 de dez. de 2020.

CORADIN, J.; BRAZ, G. B. P.; MACHADO, F. G.; DA SILVA, A. G.; SOUSA, J. V. A. de. Herbicidas aplicados em pré-emergência para o Controle de milho voluntário e capim-amargoso. Revista Científica Rural, Bagé, v. 21, n. 3, 2019. DOI: https://doi.org/10.30945/rcrv21i3.2785

DE ANDRADE, D. N. Alternativas herbicidas para o controle em pré-emergência de capim amargoso. 2019. 21f. Dissertação (Mestrado em Bioenergia e Grãos) - Instituto Federal de Educação, Ciência e Tecnologia Goiano, Rio Verde, 2019.

DA SILVA, P. V.; TRONQUINI, S. M.; BARBOSA, G. C.; DIAS, R. C.; VEIGA, J. P. S.; INÁCIO, E. M. Eficácia do herbicida flumioxazin no controle de Euphorbia heterophylla, na aplicação sobre diferentes tipos de palha e simulações de chuva. Revista Ciências Agrárias, v. 43, n. 3, p. 324-332, 2020. DOI: https://doi.org/10.19084/rca.20815

EMBRAPA_Empresa Brasileira de Pesquisa Agropecuária Centro Nacional de Pesquisa Agropecuária de Solos (Brasília, DF). Sistema brasileiro de classificação de solos. Brasília: Embrapa Produção de Informação; Brasília, DF: Embrapa Solos, 2013. 198p.

GAZZIERO, D. L. P.; ADEGAS, F. S.; SILVA, A. F.; CONCENCO, G. Estimativas de Perdas de Rendimento na Soja Devido à Interferência do capim-amargoso. Planta Daninha, Viçosa, v. 37, p. 1-10, 2019. DOI: https://doi.org/10.1590/s0100-83582019370100047.

GAZZIERO, D. L. P.; ADEGAS, F. S.; MESCHEDE, D. K.; VARGAS, L.; KARAM, D.; MACIEL, C. D. de G.; GOMES, M. de M. A era glyphosate. In: MESCHEDE, D. K.; GAZZIERO, D. L. P. A era glyphosate: agricultura, meio ambiente e homem. Londrina: Midiograf II, 2016. p. 11-21.

GRIGOLLI, J, F, J.; GRIGOLLI, M. M. K. Manejo e controle de plantas daninhas na cultura da soja. Fundação-MS, p. 130- 146, 2009. Disponível em: $<$ https://www.fundacaoms.org.br/base/www/fundaca oms.org.br/media/attachments/341/341/5e397acd682 e852c55bdafaa3136aa5e7f8aa452d6e23_04.-manejo-econtrole-de-plantas-daninhas-na-cultura-da-soja.pdf $>$. Acesso em: 13 de fev. 2021. 
HEAP, I. The International Herbicide-Resistant Weed Database. Disponível em: <www.weedscience.org>. Acesso em: 21 de set. 2020.

KISSMANN, K. G. Plantas infestantes e nocivas: tomo 1. Plantas infestantes e monocotiledôneas. 2 ed. São Paulo: BASF, 1997. 510-511p.

LAVORENTI, A.; ROCHA, A. A.; PRATA, F.; REGITANO, J. B.; TORNISIELO, V. L.; PINTO, O. B. Comportamento do diclosulam em amostras de um latossolo vermelho distroférrico sob plantio direto e convencional. Revista Brasileira de Ciência do Solo, Viçosa, v. 27, n. 1, p. 183-190, 2003. DOI: https://doi.org/10.1590/S0100-06832003000100019.

LOPEZ-OVEJERO, R. F.; TAKANO, H. L.; NICOLAI, M; FERREIRA, A; MELO, M. S. C.; CAVENAGHI, A. L.; CHRISTOFFOLETI, P. J.; OLIVEIRA, R. S. Frequency and dispersal of glyphosate-resistant sourgrass (Digitaria insularis) populations across brazilian agricultural production areas. Weed Science, v. 65, p. 285- 294, 2017. DOI: https://doi.org/10.1017/wsc.2016.31

LORENZI, H. Manual de identificação e controle de plantas daninhas: plantio direto e convencional. $7 \mathrm{ed}$. Nova Odessa: Instituto Plantarum, 2014. 255p.

MACHADO, A. F. L.; FERREIRA, L. R.; FERREIRA, F. A.; FIALHO, C. M. T.; TUFFI SANTOS, L. D.; MACHADO, M. S. Análise de crescimento de Digitaria insularis. Planta daninha, Viçosa, v. 24, n. 4, p. 641-647, 2006. DOI: http://dx.doi.org/10.1590/S010083582006000400004

MACIEL, C. D. G.; VELINI, E. D. Simulação do caminhamento da água da chuva e herbicidas em palhadas utilizadas em sistemas de plantio direto. Planta daninha, Viçosa, v. 23, n. 3, p. 471-481, 2005. DOI: https://doi.org/10.1590/S0100-83582005000300011

MATOS, A. K. A. de; CARBONARI, C. A.; GOMES, G. L. G. C.; VELINI, E. D. Dynamics of preemergent herbicides in production systems with straw. Revista Brasileira de Herbicidas, Brasília, v. 15, n. 1, p. 97-106, 2016. DOI: http://dx.doi.org/10.7824/rbh.v15i1.441

MONQUERO, P. A.; MUNHOZ, W. S.; HIRATA, A. C. S. Persistência de imazaquim e diclosulam em função da umidade do solo. Revista Agroambiente, Boa Vista, v. 7, n. 3, p. 331-337, set./dez. 2013. DOI: http://dx.doi.org/10.18227/1982-8470ragro.v7i3.1311

NEGRISOLI, E. Associação do herbicida Tebuthiuron com a cobertura de palha no controle de plantas daninhas no sistema de cana-crua. Tese (Doutorado em Área de concentração em Agricultura)- Faculdade de Ciências Agronômicas, Universidade Estadual Paulista "Julio de Mesquita Filho". Botucatu, p.1-89, 2005.

OLIVEIRA, M. F. de; BRIGHENTI, A. M. Comportamento dos herbicidas no ambiente. In: OLIVEIRA JÚNIOR, R. S.; CONSTANTIN, J.; INOUE, M. H. Biologia e manejo de plantas daninhas. 2 ed. Curitiba: Omnipax, 2011. p. 263-304.

RODRIGUES, B. N.; ALMEIDA, F. S. de. Guia de herbicidas. 7 ed. Londrina: Edição dos autores, 2018.764p..SILVA, A.A. ; FERREIRA, F.A. ; FERREIRA, L. R.Herbicidas: classificação e mecanismo de ação. In: SILVA, A. A; SILVA, J. F. (Eds.). Tópicos em manejo de plantas daninhas. Viçosa, MG: Universidade Federal de Viçosa, 2007. p. 83-147.

SISTEMA DE AGROTÓXICOS FITOSSANITÁRIOS (AGROFIT). Disponível em:
$<$ http://agrofit.agricultura.gov.br/agrofit_cons/princip al_agrofit_cons> Acesso em: 20 out. 2021.

TAKANO, H. K.; OLIVEIRA JR., R. S.; CONSTANTIN, J.; SILVA, V. F.; MENDES, R. R. Controle Químico de capim-Pé-de-Galinha Resistente ao Glyphosate. Planta Daninha, Viçosa, v. 36, p. 1-10, 2018. DOI: https://doi.org/10.1590/s0100-83582018360100055 